\title{
Wielka gra
}

\author{
Maciej Maryl
}




\section{Wstęp}

\section{Wielka gra}

Maciej Maryl

TEKSTY DRUGIE 2017, NR 3, S. 9-13

DOI: $10.18318 /$ td.2017.3.1

$\mathbf{P}$

roponując ten numer tematyczny, Tomasz Z. Majkowski

i Krzysztof M. Maj nie omieszkali uprzejmie napomknąć, że "Teksty Drugie" okazują się umowną kolebką polskiego groznawstwa. Tu bowiem w ostatnim numerze $z$ dawno zapomnianego 2002 roku (zwanego również rokiem drugim groznawstwa, jeśli liczyć od proklamacji Espena Aarsetha na łamach „Game Studies"w 2001 roku), ukazały się dwa artykuły (Rafała Szczerbakiewicza oraz Agnieszki Fulińskiej i Jakuba T. Janickiego) stanowiące symboliczny początek tego kierunku w Polsce.

Gier - jako istotnej społecznie praktyki kulturowej - nie da się już dziś ignorować. Choć brak reprezentatywnych danych dotyczących liczby graczy w Polsce, można zakładać, że jest to przynajmniej kilkanaście procent populacji. Na takie szacunki naprowadzają nas pośrednio wyniki badania segmentacyjnego uczestników kultury z jesieni 2016 roku, według którego 16\% Polaków wskazuje granie w gry jako jeden z najczęstszych sposobów spędzania wolnego czasu, a 19\% uznaje je za element kultury'. Co ciekawe, granie koreluje w tym badaniu z dwoma

1 Badanie segmentacyjne uczestników kultury przeprowadzone przez Muzeum Historii Polski, Muzeum Historii Żydów Polskich POLIN, Narodowy Instytut Fryderyka Chopina i Smartscope, http://www.nck.pl/ polskie/31900o-raport-badanie-segmentacyjne-uczestnikow-kultury/. 
postawami uczestników kultury: zdobywaniem wiedzy i relaksem - w obydwu przypadkach mocno wiążąc się z korzystaniem z szerokiej oferty kulturowej. A zatem granie jest jedną z wielu praktyk kulturowych uczestników kultury.

Ten kierunek - powiązanie grania z ogólną aktywnością kulturową - zdają się potwierdzać badania publiczności warszawskich instytucji kultury z grudnia 2016 roku, przeprowadzone wśród przeszło pięciu tysięcy uczestników stołecznych wydarzeń kulturalnych. Jako sposób spędzania wolnego czasu 11\% badanych wskazało gry (dla porównania 38\% badanych czyta w wolnym czasie książki)². Widać tu oczywiście rozwarstwienie między grupami preferującymi aktywności związane z typem rozrywki: w gry w wolnym czasie gra 8-9\% odwiedzających teatry, muzea, wystawy, koncerty, operę i balet, ale już 17\% gości ogrodu zoologicznego i Centrum Nauki Kopernik (z drugiej strony kluczowy może tu być wiek - gry są bardziej popularne wśród młodszej publiczności, która przeważa w tych ostatnich instytucjach).

Większość badań ze względu na użyteczność marketingową prowadzi się wśród graczy w gry komputerowe. Duże europejskie badanie Videogames in Europe, zrealizowane przez Ipsos MediaCT dla Interactive Software Federation of Europe w 2012 roku, pokazało, że w Polsce 49\% populacji online choć raz w ciągu ostatnich 12 miesięcy grało w jakąś grę, co daje wynik niemal odpowiadający średniej europejskiej (48\%)3. Cykliczne badania internetowe Polish Gamers z ostatnich lat szacują, że choć raz grało w jakąś grę 69-72\% internautów ${ }^{4}$. Warto jednak podkreślić, że są to badania prowadzone online i nie do końca reprezentatywne dla całej populacji. Dla porównania można przytoczyć wyniki badania przeprowadzonego telefonicznie przez Pew Research Center z 2015 roku, w którym prawie połowa dorosłych Amerykanów (49\%) stwierdziła, że grała kiedykolwiek w grę komputerową, zaś 10\% badanych uznawało się za graczy ("gamers")5. Przyjęta metodologia pozwoliła lepiej naszkicować obraz zainteresowań grami w całej populacji (amerykańskiej).

2 Badania publiczności warszawskich instytucji kultury MillwardBrown dla Urzędu Miasta st. Warszawy (Grudzień 2016), http://www.nck.pl/badania/318560-raport-z-badania-publicznosciwarszawskich-instytucji-kultury/.

3 Videogames in Europe: 2012 Consumer Study, http://www.isfe.eu/sites/isfe.eu/files/attachments/poland_-_isfe_consumer_study.pdf.

4 Badanie z 2015 roku dostępne w raporcie Kondycja Polskiej Branży Gier Wideo: http://www.kpt. krakow.pl/wp-content/uploads/2015/og/Raport_A4_Web.pdf. Wstępne wyniki badania z 2016 roku: Kim są polscy gracze? Infografika z badania Polish Gamers Research 2016, http://gry.onet. pl/artykuly/kim-sa-polscy-gracze-infografika-z-badania-polish-gamers-research-2016/gjp1mc.

5 Raport Gaming and Gamers z 2015: http://www.pewinternet.org/2015/12/15/gaming-and-gamers/. 
Warto dodać, że choć w centrum zainteresowania tych badań pozostają głównie gry komputerowe, to są jeszcze gry niewymagające komputera, jak gry RPG, karciane, escape rooms czy LARP-y, o których pisze w tym numerze Michał Mochocki. Nie zapominajmy też o starych, dobrych planszówkach. Mimo braku rzetelnych lub wyczerpujących danych możemy jednakowoż stwierdzić, że gry stanowią obecnie jedną z najpopularniejszych form rozrywki, nie powinno już zatem dziwić uznawanie ich za istotne teksty kultury. Symbolicznym awansem gier w przestrzeni kulturalnej było uzupełnienie w 2016 roku klasycznych kategorii Paszportów Polityki (literatura, teatr, sztuki wizualne, muzyka poważna i popularna) o "kulturę cyfrową", którą w pierwszej edycji zdominowały właśnie gry.

Podczas niedawnej konferencji Cultural Literacy in Europe w Instytucie Badań Literackich PAN Espen Aarseth mówił wręcz o ciekawych praktykach kulturowych, które z jakiejś przyczyny nazywamy grami (a nie na odwrót). A zatem to w jakimś sensie ewolucja kultury kazała nam myśleć o tych tekstach odmiennie niż o książkach, filmach, spektaklach... Może czas to zmienić? Na gry powinniśmy patrzeć tak jak na inne teksty kultury, które powstają i ewoluują w kontekście dostępnych technologii komunikacyjnych. W ten sposób np. blogi można traktować jako powrót (czy też postdrukowe nawiązanie) do sytuacji komunikacyjnych sprzed epoki druku - udrożnienie bezpośrednich kanałów komunikacji, rozwój lokalności, aktywizację czytelników itd. Podobnie dzisiejsze seriale wysokobudżetowe w ciekawy sposób wchodzą w dialog z kinem i z gatunkiem powieści. No i mamy wreszcie gry, które łączą opowieść z elementem growym - pozwalają nam w nią ingerować, przywracają poczucie kontroli, odwołują się do chęci współzawodnictwa, stopniują ciekawość...

$Z$ radością przystaliśmy zatem na świętowanie 15-lecia polskiego groznawstwa na naszych łamach. Zwłaszcza że czuliśmy się nieco współodpowiedzialni za nieoczekiwany owoc naszych decyzji redaktorskich sprzed lat. Proszę sobie więc wyobrazić nasze zdziwienie, gdy do tomu na cześć piętnastolecia groznawstwa dostaliśmy tekst o... ćwierćwieczu polskich badań nad grami. Oczywiście, jak to zwykle bywa z nowymi kierunkami - tych początków jest zazwyczaj kilka i trzeba sobie jakiś wybrać. W tym wypadku skrzętnie katalogują je nieocenione bibliografie tworzone przez Stanisława Krawczyka i Roberta Dudzińskiego. Marii B. Gardzie natomiast zawdzięczamy odnalezienie w mrokach transformacji ustrojowej owego przedćwierćwiecznego, pierwszego polskiego tekstu groznawczego autorstwa Ryszarda Ciarki, pod jakże barthes'owskim (a przez to i nieco manifestowym) tytułem: Śmierć kina.

Groznawstwo gra w wielką grę. Podobnie zresztą jak wiele innych młodych prądów, kierunków, zwrotów, przewrotów, powrotów i nawrotów. Stawką w grze jest oczywiście uznanie dla danego kierunku (dyscypliny? - tu odsyłam do polemik zawartych w numerze) oraz jego instytucjonalizacja. Budowanie rodowodu to tylko jeden ze 
zwyczajowych elementów tej gry. Celem tego numeru z pewnością jest nie tyle prezentacja bogactwa podejść, ile wyjście poza zwykły krąg adresatów badań groznawczych - do szerszego środowiska literaturoznawców i kulturoznawców, dla których nowość mogą stanowić nie tylko prezentowane tu badania, lecz także - i to prawdziwe wyzwanie - sam ich przedmiot...

To zaiste sytuacja osobliwa, ponieważ z jednej strony gry zdają się stanowić osobne "medium" (w szerokim znaczeniu), rządzące się swoimi własnymi prawami, jak literatura, sztuki plastyczne, film, muzyka... Z drugiej, za sprawą hybrydowej formy i narracyjności, stanowią wdzięczny przedmiot do analiz z wykorzystaniem narzędzi strukturalistycznej i poststrukturalistycznej teorii literatury, o czym mogą świadczyć odniesienia autorów prac tego tomu do takich postaci jak (w kolejności alfabetycznej): Bachtin, Bal, Bourdieu, Derrida, Doležel, Eco, Foucault, Gadamer, Genette, Greenblatt, Heidegger, Hillis Miller, Hutcheon, Iser, Latour, Markiewicz, Markowski, Mouffe, Nünning, Ricœur, Said, Sławek. W zasadzie brakuje tu tylko dwóch nazwisk: Ingardena i Okopień-Sławińskiej. Pierwszego - choć jestem jak najdalszy od stwierdzeń, że cała kognitywistyka to tylko przypisy do Ingardena - ponieważ multimodalny charakter doświadczeń graczy zdaje się dobrze współgrać ze skrajnie ejdetyczną koncepcją konkretyzacji, którą na gruncie literatury postponował Lem, argumentując, że on sobie niczego nie wyobraża, czytając. Może właśnie gry okazałyby się ciekawym przedmiotem badawczym dla tej koncepcji. A druga, jako symbol systematycznej poetyki strukturalnej, która - zdać by się mogło - może często dostarczać lepszych narzędzi analitycznych niż popularna narratologia Mieke Bal.

Prace zebrane w tym tomie dowodzą użyteczności stosowania w analizie gier narzędzi wypracowanych przez literaturoznawstwo. Mamy tu z jednej strony propozycje metodologiczne, czerpiące z hermeneutyki (Kłosiński), narratologii (Felczak, Maj), Bachtina (Majkowski), paratekstualności (Żmuda, Kominiarczuk) czy krytyki posthumanistycznej (Fizek, Stasieńko). Z drugiej, znajdziemy tu teksty stanowiące klasyczne interpretacje odwołujące się do krytyki ideologicznej (Schweiger), postkolonialnej (Kukulak), Heideggera (Kania), Derridy (Błaszkowska) czy Foucaulta (Zarzycka). Wyraźnie widać, że nie chodzi tu jednak o zwykłe przykładanie narzędzi do nowego przedmiotu, tylko o wypracowanie konkretnej metodologii badawczej - świadczą o tym zmagania groznawców z językiem, by odpowiednie dać grze słowo. W efekcie powstaje dość hermetyczny, ale własny zestaw terminów (często wędrujących z innych dyscyplin lub języków): protagonista, postać grywalna, immersja, awatar, groznawstwo, materiał growy, emergencja, cutscena (katscena?), gameplay (gejmplej?), agentywność itd. O tym, że groznawstwo wchodzi w fazę instytucjonalizacji, świadczą nie tylko skrupulatnie odnotowane nowalijki archiwalne (Garda i Krawczyk, Mochocki), lecz także temperatura polemicznej wymiany ognia między różnymi ujęciami dyscypliny przy okazji 
trójgłosu wokół książki Katarzyny Marak i Miłosza Markockiego Aspekty funkcjonowania gier cyfrowych we współczesnej kulturze. Studia przypadków (Rorot; Krawczyk, Sterczewski i Kominarczuk; Marak i Markocki). Trudno się jednak dziwić, ponieważ wielka gra toczy się tu o wielką stawkę. Chodzi o, ni mniej, ni więcej, uświadomienie szerokiej publiczności, że gry (zwłaszcza komputerowe) to nie tylko pełnoprawne teksty kultury, które warto badać (to już chyba wiemy, o czym świadczy niemała bibliografia polskich tekstów czy wystąpień konferencyjnych w tej materii), lecz także pewna forma uczestnictwa w kulturze, bez znajomości której już wkrótce trudno będzie nam rozumieć współczesne społeczeństwo.

\section{Abstract}

\section{Maciej Maryl}

THE INSTITUTE OF LITERARY RESEARCH OF THE POLISH ACADEMY OF SCIENCES (WARSAW)

The Name of the Game

Maryl frames the articles collected in this volume as examples of how the tools of literary studies can be applied to game analysis. While Polish Game Studies are aspiring for recognition as a field, the key issue is to make the general public aware that games (especially computer games) are not just fully fledged cultural texts worth exploring, but that they have also become an important way to participate in culture. This form of participation, Maryl suggests, will soon be crucial for understanding modern society.

\section{Keywords}

game studies, literary studies, research, gamers, contemporary, Polish culture 